\title{
THE PREVENTION OF FETAL ALCOHOL SPECTRUM DISORDER: THE NEED FOR A COORDINATED SERVICE BY ROLE PLAYERS IN THE WINE PRODUCING AREAS IN THE BREEDE RIVER VALLEY
}

\section{Marlene de Vries, Sulina Green}

\section{INTRODUCTION}

Fetal Alcohol Syndrome (FAS) is seen as the leading preventable birth defect in the western world (May, Miller, Goodhart, Maestas, Buckley, Trujillo \& Gossage, 2007). FAS is the severe end of a spectrum of effects caused by alcohol intake during pregnancy and is characterised by unique facial features, growth retardation and developmental delays (May, Gossage, Marais, Adnams, Hoyme, Jones, Robinson, Khaole, Snell, Kalberg, Hendricks, Brooke, Stellavato \& Viljoen, 2007; Urban, Chersich, Fourie, Chetty, Olivier \& Viljoen, 2008). Drinking alcohol during pregnancy has physical, behavioural and mental consequences for the developing fetus. These effects last throughout the lifespan of the individual with a Fetal Alcohol Spectrum Disorder (FASD).

The highest recorded prevalence rates of FAS in the world have been reported in South Africa, where the prevalence rate of FAS was 68.0 - 89.2 cases per 1000 births in a high risk community in the Western Cape Province (May et al, 2007:267). Preliminary figures from a recent study in the wine producing areas of Bonnievale, Robertson, Ashton and Montagu, which formed the study community for this study, indicated a prevalence rate of 94 to 129 per 1000 children (May, 2011).

Compared to an average of eight per 1000 in certain high risk communities in the United States of America and an average estimate of 0.97 in the developed world, according to May et al. (2007), this gives an idea of the extent of the problem in South Africa, and especially the Western Cape. May et al. (2007) have described the prevalence of FAS as extremely high overall, but highest in the impoverished rural areas of the Western Cape.

Various studies (May, Gossage, Marais, Hendricks, Snell, Tabachnick, Stellavato, Buckley, Brooke \& Viljoen, 2008; May et al., 2007) have shown that a high percentage of women continue their drinking pattern during their pregnancy. May et al. (2007) also describe this drinking pattern is as a drinking culture where heavy weekend drinking or binge drinking is characteristic. According to Falletisch (2008) many farm workers drink to intoxication over weekends and underestimate the amount of alcohol which they consume. FAS and the dangers of drinking alcohol during pregnancy are, however, not unknown concepts to the general population in the study area. A community survey conducted at the same time as the above-mentioned study by May (2011) indicated that $86.5 \%$ of women and $66.7 \%$ of men in the study area had previously heard of FAS (Parry, 2011). This survey further indicated that $90.1 \%$ of women and $81.1 \%$ of men in the study area were of the opinion that no amount of alcohol is safe during pregnancy (Parry, 2011). 
Drinking during pregnancy has severe consequences: learning disabilities, characteristic facial features and damage to the nervous system, organs and limbs, which remain with children with FAS for life (Marais, 2006). This author further states that FAS is a significant health problem in South Africa and, if the whole spectrum of disorders that may result from the use of alcohol in pregnancy is taken into account, the problem is even bigger. That makes efforts towards prevention all the more important.

According to Chambers (2006) prenatal alcohol exposure is a substantial public health concern. Already in 2004 McKinstry (2004:3) stated that the South African health authorities should restructure health care systems and strategies to address the "epidemic" of FAS in the Western Cape. He concluded that "...a holistic, comprehensive approach will be necessary to begin reversing a trend that has been developing for 300 years". In order to follow a comprehensive approach in the Western Cape, professionals of different disciplines will need to work together in an organised and planned manner to achieve the necessary impact. A comprehensive approach for the prevention of FAS in South Africa has to consider the input of multiple disciplines and community organisations and structures, as well as prevention components on primary, secondary and tertiary levels of prevention (May et al., 2007).

This line of reasoning is confirmed in an article compiled by a working group of the Alberta Partnership on Fetal Alcohol Syndrome (1999) in the USA, which says that "...the goal of a comprehensive prevention program is to provide overlapping levels of reinforcement (education and persuasion), incentives and interventions to prevent FAS". The idea of overlapping levels for prevention is based on the ecological perspective of the individual as a part of different systems in his/her environment which continually influences each other (Ott, Quinn \& Thompson, 2004).

In the discussion of the study conducted on the epidemiology of FAS in the Western Cape by May et al. (2007), the researchers state that comprehensive approaches utilising universal education and broad behavioural change techniques will benefit from an infusion of resources and consistent organisational support. They further say that specific, targeted intervention using selective approaches, as well as indicated prevention utilising case management for maternal support and guidance in a poorly educated population, are needed.

The Institute of Medicine (IOM) Model also recommends a comprehensive approach to the prevention of FAS (May et al., 2007). Overlapping levels of reinforcement on different levels of prevention are needed to apply a comprehensive approach to prevention programmes (Stratton, 1996). This author also refers to the different levels of intervention as an intervention spectrum for FAS. Three levels of intervention into which prevention can fit have been identified:

1) Universal prevention. This level of prevention is also known as primary prevention; it attempts to educate the broad public or an entire population group. At this level, prevention includes public service announcements, posters, pamphlets, media advertisements and the discussion of contraceptive strategies with men and women (Alberta Partnership on Fetal Alcohol Syndrome, 1999; Hankin, 2002). According to 
Stratton (1996), it seems that universal prevention activities increase general knowledge about FAS and the consequences for the child who is prenatally exposed to alcohol.

2) Selective prevention, also known as secondary prevention, targets individuals with a significantly higher risk of bearing a child with FAS. Such methods of prevention include screening women of childbearing age who abuse alcohol, as well as early prevention programmes, such as counselling (Alberta Partnership for Fetal Alcohol Syndrome, 1999; May et al., 2007). Stratton (1996) suggests that selective prevention during pregnancy can stop some women from drinking during pregnancy. There are no clear indications, however, to identify the group of women who will respond to these prevention efforts.

3) Indicated or tertiary prevention is defined as those prevention efforts that are directed at individuals with a predisposition for a certain condition (Stratton, 1996). In FAS prevention, this description refers to high-risk women who are drinking heavily whilst pregnant or who are known to have a previous child with FAS (May et al., 2007). Prevention at this level includes brief interventions, case management or referral to inpatient or outpatient treatment centres (Hankin, 2002; May et al., 2007). Case management is described by May et al. (2007) as a key intervention and as efficacious with women who run a high risk of giving birth to a child with FAS.

Although FAS prevention efforts exist in social work practice, they mostly are fragmented awareness programmes on a primary prevention level and do not provide the necessary "...overlapping levels of reinforcement" (Alberta Partnership on Fetal Alcohol Syndrome, 1999). Being involved in a comprehensive epidemiological study on FAS currently, one would realise the necessity of a multi-disciplinary and multi-level approach by professionals in the fields of social work, health and education, as well as input from community sources such as churches, in the prevention of fetal alcohol syndrome, especially in communities with a high prevalence of FAS.

\section{PROBLEM STATEMENT}

Various studies (May et al., 2007; Viljoen, Gossage, Brooke, Adnams, Jones, Robinson, Hoyme, Snell, Khaole, Kodituwakku, Asante, Findley, Quinton, Marais, Kalberg \& May, 2005) confirm the extremely high prevalence of FAS in the Western Cape. Literature confirms the need for a comprehensive approach to prevention activities on primary, secondary and tertiary levels over a wide spectrum of disciplines such as health, education and social work (Astley, 2004; May et al., 2007). FAS places a huge strain on the already limited resources of the health care, educational, social welfare and judicial system, as well as on job creation (Chambers, 2006; Miller, 2005). Prevention efforts are still fragmented, however, and do not address the realities of FAS extensively. According to Parry (2005:24), a national integrated strategy or policy for the prevention for FAS is needed. Such a policy must bring together a coordinated response which includes civil society (Parry, 2005:24). It would, therefore, benefit the social work profession to explore and gain insight into how a coordinated service could be rendered by role players in a wine producing area in order to deliver a more comprehensive service on all the different levels of the environment. 


\section{AIM OF THE RESEARCH}

The aim of this research was to create understanding of how different role players could contribute to a coordinated service for the prevention of FAS.

\section{RESEARCH METHODOLOGY}

For the purpose of this study, a mixed methods approach was deemed appropriate to create the opportunity to both describe current prevention efforts and explain the need for a multi-disciplinary approach to the prevention of FAS in rural wine producing communities.

By making use of a mixed methods study which included a literature study, interviews and the use of knowledgeable professionals as sources of information, this study aimed to gain insight into and comprehension of the research topic.

Non-probability sampling, specifically purposive sampling, was used. The study population consisted of professional people and service providers in the fields of health, social development, education, safety and security, as well as community development, all of whom have been involved in the prevention of FAS in the studied communities. The above-mentioned aspects, namely being professional people or service providers in the fields of health, social development, education, safety and security, and community development, and involvement in the prevention of FAS in the studied communities, were the criteria for participation in the study. The majority of the sample participating in the study was from the fields of social development and health, since these are the fields primarily concerned with the phenomenon of FAS. The rest of the study population included a few individuals who were involved in FAS prevention efforts in the studied communities.

The community on which the study was focused involved the towns and surrounding farming areas of Robertson, Ashton, Montagu and Bonnievale. The sample of 22 professional people working in these areas was from the fields of health, social development, community development, education and safety and consisted of five social workers from NGOs and one from Hospice; the CEO of FAS Facts; the development worker of the Rural Development Forum in one area; one police official involved with social crime prevention; a school psychologist and a social worker from the Department of Education; the coordinator of the alcohol and drug programmes of the Department of Social Services; a senior official and a sonographer from the Department of Health; six nursing sisters in charge of clinics; the programme manager of the Fetal Alcohol Syndrome Epidemiological study conducted in the study area by the University of Stellenbosch in collaboration with the University of New Mexico in the USA; and the Head of a children's home.

Data were collected by means of semi-structured one-on-one interviews. In this study, which was focused on the experiences and informed opinions of professionals and active participants in the field of FAS prevention as the source of information, the participant was perceived as the expert on the subject and the interview schedule guided, rather than dictated, the interview. All participants granted permission for the interviews to be 
audio-recorded. The interviews were conducted in Afrikaans, which was the home language of all the participants. All interviews were conducted between May and July 2011.

The data collection of this study commenced with audio-recordings of the interviews and the writing of field notes during and directly after each interview. The audiorecordings were transcribed and general themes and sub-themes were identified. Closed questions in the questionnaire were also analysed before the data were summarised, interpreted and compared with the literature study.

\section{RESEARCH FINDINGS}

The data collected from the above-mentioned interviews was used to do an investigation of existing FASD prevention services offered by welfare organisations, health services, law enforcement services, education, a NGO specialising in FASD prevention services and a joint research study conducted by the University of Stellenbosch and the University of New Mexico. Findings are based on the data obtained from questionnaires used in the semi-structured interviews and are presented with an interpretation of the data in comparison with literature.

\section{Identifying details of participants}

The majority (8, or $36 \%$ ) of the participants were trained social workers. Five (23\%) of the participants were working in the field of health services. Most participants were employed in senior positions and were knowledgeable about the services their organisations offered. The majority of the participants $(20$, or $91 \%)$ had tertiary qualifications; $13(59 \%)$ had university degrees and seven (32\%) had obtained college diplomas. The remaining two (9\% of the participants) completed high school.

The results of the study also indicate that eight (36\%) participants were primarily involved with health services and six (27\%) participants indicated welfare services as their core business. The other core functions that were indicated were education (two, or 9\%); FAS awareness and prevention (two, or 9\%); law enforcement; rural development; care of terminally ill patients; and full-time care of children in a children's home (one, or 5\% each). Two (9\%) of the participants were of the opinion that their core business stretched over two fields, but they eventually indicated the most important of the two fields.

\section{Prevention services}

In the section of the questionnaire which dealt with prevention services, participants first had to indicate whether their organisation or government department was involved in the prevention of FAS. Following this, they had to indicate the levels on which prevention services were available and what these services comprised. A total of 20 (91\%) participants indicated that their organisations were involved with the prevention of FASD to some extent, while two (9\%) said that they did not deliver FASD prevention services themselves, but that their involvement only consisted of attending and supporting the services of other role players. 
- Universal prevention services

May (1995), states that public education is one of the basic techniques used in universal prevention. Education on the adverse effects of alcohol to the unborn child can be provided by using electronic and printed media in all primary institutions, such as families, schools and churches.

Examples of universal prevention services were listed and participants in this study were asked to indicate whether their organisations offered any of these services. The services listed included general awareness programmes in the community, i.e. marches, newspaper articles, and awareness programmes for children, teenagers, women or men. Then the participants had to describe the universal prevention services which they offered. Ten $(46 \%)$ participants indicated that their organisations offered no universal prevention services. Six (27\%) participants indicated that their organisations or government department offered several universal prevention services. Participants described the following universal prevention services in which they were involved:

"Community radio stations and advertisements where the message is given that a mother must not drink alcohol while she is pregnant."

"An annual sounding of bells in the different towns.",

These services are in accordance with the universal prevention techniques and approaches described by May (1995). Most of the universal prevention efforts described by the participants were focused on women, while only five $(22 \%)$ of the participants mentioned prevention efforts aimed at men. This indicates a gap in service delivery since, according to May (1995), public efforts and prevention methods should be aimed at both men and women to convey a clear message about the mutually complementary roles of the two sexes in preventing FASD.

Another four participants $(18 \%)$ indicated that, although they did not offer universal prevention services themselves, they engaged in universal prevention services of other organisations in the following way:

"We will engage in programmes in the community but have never been the initiators ourselves."

From the description of services offered, it was clear that the participants were inclined to describe all universal prevention services their organisations offered and not only those aimed at the prevention of FASD. Although it was explicitly explained that this study was not an evaluation of their services or a test for their competency, some participants still described programmes with a completely different aim, but with an occasional input relating to FASD, as is reflected in the following statements:

\footnotetext{
${ }^{1}$ Church and school bells are annually sounded on on 9 September (International FAS day), to remind women not to drink during the 9 months of pregnancy.
} 
"You address alcohol abuse...."

"We will usually focus on one of the aspects which is linked to health or social circumstances."

The involvement in universal prevention activities concerning FASD reflected in the above-mentioned responses indicates that FASD in many instances is still addressed as a sub-theme of alcohol abuse or included general programmes to enhance social functioning. Although this way of addressing FASD is in accordance with the findings of May et al. (2008), who state that many of the risk factors for FASD are amenable to change via social improvement, these authors still recommend that FASD prevention should be formally and actively pursued in the community. On the level of universal prevention, the results of this study indicate a lack of such formal programmes that are actively pursued in the community.

\section{- Selective prevention services}

According to Marais (2006), routine screening and brief interventions in antenatal clinics provide an effective, low-cost means of helping pregnant women to reduce or eliminate alcohol use during pregnancy.

In this study thirteen (59\%) participants, of whom eight (36\%) were involved in health services, indicated that their organisations were mainly involved in short interventions with pregnant women. These short interventions with pregnant women were offered by the clinics, the sonographer in the area, FAS Facts and a research study operating in the area. The use of short interventions is in accordance with literature such as the Alberta Partnership on Fetal Alcohol Syndrome (1999) which describes pregnancy as the ideal time for the physician to identify a drinking problem and to intervene. May (2011) emphasises the importance of interventions during pregnancy and refers to pregnancy as a "teachable moment".

Where short interventions with pregnant women were offered, the content of the conversations in the clinics were described as:

"What damage it can do to the baby."

Some of these conversations did not focus on fetal alcohol syndrome at all, however, but on alcohol abuse. This is illustrated by the following narrative:

"I will talk to her about her alcohol abuse, but not necessarily fetal alcohol syndrome."

Social worker participants were only involved in short interventions with women who were already on their case loads and as part of their general social intervention, but not as a planned fetal alcohol prevention service. This finding is illustrated in the narrative below:

"The case load was too... is too big."

It can therefore be said that the responsibility for selective interventions in the studied area mostly resides with health care providers. This is in accordance with the view 
expressed by Stratton (1996), who stated that health care providers should deliver selective interventions and intervene in a timely and meaningful manner.

\section{- Indicated prevention}

According to the Alberta Partnership on Fetal Alcohol Syndrome (1999), a more direct approach is needed if a change in drinking behaviour is not evident in short interventions. May et al. (2007) describe case management and using motivational interviewing techniques as a key factor for the successful prevention of FAS.

Fifteen (68\%) participants in this study indicated that they were offering some form of individual counselling. In the clinics this counselling was offered in the form of short conversations. Where pregnant women received individual counselling by social workers, it was offered to women on their existing case loads. These services were also not focused on high risk pregnant women, but consisted of general information given during counselling and were not handled as planned or specific interventions with high risk pregnant women:

\section{"There is not a specific treatment program that we use for pregnant women who abuse alcohol."}

This is in contradiction to the advice given by Stratton (1996) that high priority must be given to interventions that can effectively guide women who drink heavily through pregnancy. This should, according to Stratton (1996), include counselling the woman and her family, as well as referral of high risk women for counselling or treatment. Fourteen $(63 \%)$ participants indicated that they referred pregnant women who drink for counselling or treatment. Some participants, however, indicated that they do not refer regularly.

Other participants revealed that they refer to social workers, but that there is a lack of support from social service providers, as well as a lack of trust in the ability of social workers to follow up on these referrals. This was emphasised by a comment from one of the participants:

\section{"I can truly say that we get very little support."}

The quoted comments suggest that there is a void in the delivery of indicated prevention services. May (1995) stresses the importance of matching each of the levels of prevention with an aggregate level of maternal drinking and other risks in order to effectively address the risks, causes and outcome of FASD. The importance of the indicated prevention services and the fact that it should not be compromised is emphasised by this statement. May (1995) also stresses that all the levels of prevention should be addressed to maximise the impact of prevention services on a community.

\section{Collaboration and co-ordination with other role players}

In the section of the questionnaire which focused on collaboration and co-ordination with other role players, it was determined whether organisations, government departments and individuals collaborated in the delivery of FASD prevention services; 
whether there was co-ordination between the parties; and how collaboration and coordination was taking place.

- Collaboration with other role players

Figure 1 reflects the participants' opinions about their collaboration with other organisations, government departments and individuals.

FIGURE 1

COLLABORATION WITH OTHER ORGANISATIONS

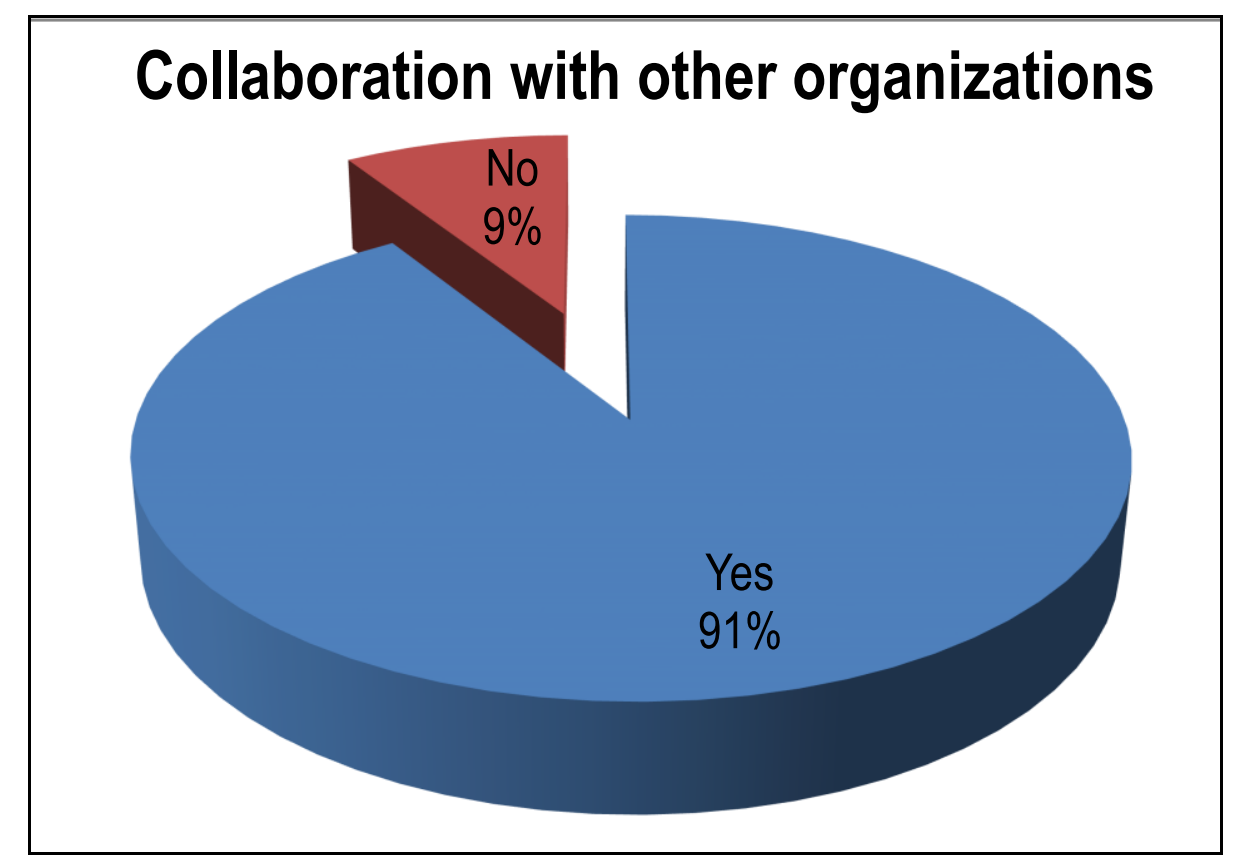

$\mathrm{n}=22$

As seen in Figure1, an overwhelming majority (20, or 91\%) of the participants indicated that they collaborated with other organisations or departments. Participants who responded positively named collaboration with NGOs, clinics, various government departments, rehabilitation centres, research groups, the local municipality, the Lotto, South African Breweries, and organisations such as Pebbles ${ }^{2}$ and Dopstop ${ }^{3}$. When asked to describe how they collaborated, the comments of participants included:

"We absolutely give our support to their programme in the schools."

"We just join in with their programmes."

"If we have an information session or something, we invite the social worker or she invites us to join them."

The narratives quoted above clearly indicate that organisations show support for and join in with each other's programmes. They also invite other organisations to join their

2 A NGO supporting children with special educational needs as a consequence of alcohol-related dysfunctions.

3 A NGO supporting personal and social development through providing information, education for health and life enhancing skills. 
programmes. These comments reveal general positive relationships between organisations, government departments and individuals in the field of FASD prevention services. It also shows sensitivity not to duplicate services, but provides no proof of active collaboration to enhance the quality and range of services.

Active collaboration and comprehensive programmes are much needed for successful prevention programmes, however. Although there is positive movement towards collaboration, these findings do not support the opinion expressed by May (1995) that effective prevention programmes should use broad bases of knowledge and several perspectives to carry out community-wide prevention programs.

- Co-ordination with other role players

Participants were asked whether their organisations' FASD prevention services were coordinated with those of other organisations, departments and individuals. Only nine (41\%) participants were of the opinion that services were co-ordinated between organisations. However, when asked how these services were co-ordinated, the responses varied. Some participants saw sharing dates of events or inviting other organisations to their events as co-ordination. This can be seen from the comment presented below:

"...gave our dates in advance to all the others and they gave us theirs and in that way we joined in with each others' programs and it worked well."

Two participants (9\%) mentioned the existence of co-ordinating committees such as welfare forums:

"We are part of the regional welfare forum in which all the social workers in the area are included."

"It is the substance abuse forum or co-ordinating committee or something for which we get representatives from all the organisations together."

Other participants however, denied the existence or were unaware of such co-ordinating committees as expressed by one participant:

"Not that I know of - whether there is an overall committee - and if there is, I am not aware of it."

There were participants, however, who said that they do co-ordinate, but did not have much faith in the co-ordination. This was expressed in the following narratives:

"You will get one or two NGOs who will take hands because they share the same field of interest, but my feeling is that it is the absolute minority."

"On FAS Day you might do something together but that is where it starts and ends."

Several of the findings revealed that, although there was co-operation between organisations, there was no formal co-ordination. Existing co-ordination was also described as loose and informal: 
"I think it was more of a loose co-ordination."

"Yes, I'll say it is more of an informal co-ordination, yes."

"Not really co-ordinated, no."

The diversity of opinions about co-ordination again points toward a general willingness to co-operate with other organizations and role players, but only on the level of attending each other's projects, taking cognisance of dates for which other role players planned projects and giving each other support by allowing certain organisations to work in schools or clinics, for instance. It would seem that those comprehensive approaches that combine various levels of prevention and multiple approaches are not rare in literature only, but also in practice (May \& Hymbaugh, 1989). May (1995) also states, however, that all major institutions should, whenever possible, be tapped and utilised as agents of change. This kind of collaboration is also the aim of the Integrated Service Delivery Model (ISDM) (South Africa, 2006) which has adopted a developmental approach to service delivery. This approach requires services to be intersectoral and that the different government departments and sectors integrate their services.

The ISDM (South Africa, 2006) calls on government departments to co-ordinate their policies and to follow a holistic approach to address the complex and multi-dimensional social issues in our society. This approach requires the different departments to understand the roles and responsibilities of one another. It further requires integrated developmental efforts between departments, as well as integrated efforts on the different levels of the social environment. Finally, it also is requires the use of all three levels of prevention.

\section{Referral}

With regards to the system of referrals between non-government organisations and government departments, the findings of the study show that there either was no formal system of referrals or that the participants did not know about the existence of such a system:

"Well, if you know about it and I don't know about it, you must tell me."

"There are no formal agreements."

Participants also agreed on the fact that referrals take place on an informal basis between the different role players:

"I would say it is informal between people - between specific people who deliver services."

Referrals, however, come with their own frustrations and, in some cases, cause people to fall through the system and not get the services they desperately need. This is, as one participant stated, caused by a lack of support from other organisations or departments and a lack of resources: 
"We don't have support from Social Development. We don't have enough psychologists, so I don't think we have enough resources to which we can refer. No, I know this for sure. It would be wonderful if we had enough resources to address the problem. You see, it is very easy to say do this or do that, but yes, what do you have to do, where do you refer to? We don't have anybody."

The frustrations caused by the above-mentioned informal or, according to some participants, non-existing system of referrals is also addressed and supported by literature. Marais (2006) advises that appropriate referral systems have to be put in place to increase the efficacy of interventions. May (1995) furthermore states the importance of empathic and motivational referral, especially of those women who are resistant to services, as well as the importance of ensuring that women who are heavy drinkers receive first priority for enrolment in alcohol treatment programmes. From the findings discussed above, it is clear that there is a need for an appropriate referral system.

With regards to the referral of service users to any other role player during the preceding year the largest number (13, or 59\%) of participants never referred service users to any other service provider to provide a FASD prevention service. Another two (9\%) participants had referred to another service provider just once during the preceding year. Three (14\%) of the participants made quarterly referrals. Only one $(5 \%)$ of the participants made weekly referrals and three (14\%) of the participants referred monthly.

These findings are in contrast with the literature which suggests that voluntary referral to therapy for alcohol abuse should be pursued empathically but aggressively (May, 1995) and that an appropriate interventional or treatment referral must be made as soon as a problem is identified by the health care worker (Stratton, 1996).

The service providers to whom participants referred service users to, are reflected in the following comments of participants:

"Normally when it comes to the point where it is about medical aspects, we will refer to a doctor."

"Yes, see if we pick up something we will refer to the ACVV ${ }^{4}$."

"We refer to Social services, to FAS (Fetal Alcohol Syndrome Epidemiological Research), to Home Base(Home Based Care), to BRAM (BRAM Care Centre), to the police, to the court or to the school psychologist."

These referrals to service providers of different disciplines are supported by literature because May (1995) states that quality treatment, which should be based on both behavioural and medical therapy, is a very important part of the overall solution to substance abuse problems. However, referring service users with medical problems or social problems only, as indicated by participants in the above narratives, is not in accordance with literature. The importance of combined efforts by various disciplines to prevent FASD is accented repeatedly in literature (Miller, 2005; Parry, 2005).

${ }^{4}$ A private welfare organization (NGO).

${ }^{5}$ A NGO that takes care of terminally ill patients.

Social Work/Maatskaplike Werk 2013:49(3) 


\section{Obstacles in service delivery}

Participants were asked what they saw as obstacles in the delivery of FAS prevention services. A wide variety of obstacles were mentioned, since the participants had different perspectives on FASD due to their fields of service. These included the following:

- A lack of family planning

- Women who drink do not use their contraceptives regularly

- Shortage of resources such as funding and human resources

- Personnel in clinics and social workers felt overwhelmed by the magnitude of the needs they have to tend to

- A lack of training for both professional people and volunteers working in the community was a recurrent theme

- In the experience of the participants, certain factors in the community also influenced women's decisions about drinking during pregnancy. This included the culture of alcohol use and abuse, especially over weekends; the difficult social conditions of many women; the fact that some women find it hard to cope with their circumstances; the failure of the community to speak out when pregnant women are drinking; the inherent lack of motivation in some women; and the lack of support for pregnant women to stop drinking.

- Participants also described a lack of co-ordination between organisations in the field of FAS prevention as a serious obstacle in the delivery of effective FAS prevention services ("...There is not co-ordination between all the organisations that exist."). A need for better co-operation was also expressed ("...Your different government departments must join hands with these types of programs or you'll only reach a small proportion of the people.") Some participants saw this lack of co-ordination and co-operation as due to uncertainty about each others' roles ("Maybe we should look at what everybody's roles are and if everybody is fulfilling their roles.").

These findings, as presented above, correlate with literature. Co-ordination of activities and relationships between various non-government organizations and government departments, according to May (1995), is generally insufficient. Although this state of affairs is not unique to the Western Cape of South Africa, this area with its extremely high prevalence of FASD, cannot afford a lack of co-ordination and co-operation between role players to harm prevention efforts.

\section{DISCUSSION AND RECOMMENDATIONS}

The twenty-two participants in this study were professional people who were either involved in the prevention of FASD or were working with people who have been affected by alcohol during pregnancy. The participants each described the different FASD prevention services that their organisations rendered on all levels of prevention. From these descriptions, it was clear that a wide variety of universal prevention services was available in the studied area. These services were mostly focused on women and children, however, and few services included men or highlighted the role of the father during pregnancy. It was also clear that only a small proportion of the participants were 
actively involved in universal prevention services. A sizeable proportion engaged in the universal prevention services of other organisations, but never initiated any prevention services themselves. Almost half of the participants never attempted or engaged in any universal prevention services.

Selective prevention services were mostly offered by health care workers and social workers whose caseloads included pregnant mothers. The content of their short conversations, however, often focused on alcohol abuse and not on planned short interventions to prevent fetal alcohol syndrome. This was especially true in the case of social workers who considered this the task of the local clinics. Although several participants indicated that they were involved in indicated prevention services, these services mainly consisted of giving general information while counselling women who already formed part of the case loads of social workers. Some health workers also regarded follow-up conversations with pregnant women as indicated prevention services. No planned or specific interventions with high-risk pregnant women in the study area were indicated. Given the extremely high prevalence of FASD in the Western Cape, this is a serious shortcoming in prevention services.

Several obstacles in the delivery of prevention services were pointed out. The ignorance of individuals, the community and, in some cases, government structures, caused immense frustration for those who are trying to deliver a service without the necessary resources. Participants strongly emphasised the need for drastic measures and more aggressive prevention programmes to break the vicious cycle of FAS in these high-risk communities.

Participants in this study described a shortage of resources consisting of insufficient funding and human resources, as well as training and training materials. Insufficient funding handicaps the services of NGOs in particular, whereas a shortage of human resources results in personnel feeling overwhelmed by their workload. This leads to the conclusion that insufficient funding and a lack of human resources limits not only the variety of FASD prevention services, but also the effectiveness of these services.

Collaboration and co-operation between different role players proved to be a major cause of concern. A lack of co-ordination, uncertainty about the roles of different roleplayers and a lack of co-operation was identified by the participants as obstacles in the delivery of FASD prevention services. Although general relationships between organisations were good, hardly any formal collaboration agreements existed between them. Organisations attended each others' programmes and considered each other in their planning, but co-ordination was rare. This affected referrals and the degree to which organisations trusted one another to deliver the services they were supposed to deliver. This has led to the conclusion that there is not only a need for co-ordination, but that a lack of co-ordination between non-government organisations and government departments involved in FASD prevention services is an obstacle in the delivery of effective FASD prevention services.

Regarding referral, the general consensus of participants in this study was that no formal referral system exists between role players in the field of FASD prevention. The study 
found that almost $60 \%$ of participants never referred individuals or groups that needed services to other role players. The study also indicates that a lack of support from welfare services, a shortage of psychologists, and of resources, in general, influenced referrals. It can therefore be concluded that there is a need for a formal system of referrals, as well as a need for dependable resources to increase the efficacy of interventions.

In the light of the results of the investigation concerning FASD prevention services and the coordination of such services by role players, the following recommendations are made:

- Non-government organisations and government departments involved in the prevention of FASD must define their specific aims for, and roles in, the prevention of FASD according to their specific knowledge base and skills to address the aspects of FASD that they are best qualified to address.

- All the major role players, such as the Departments of Health, Education, Social Services, Safety and Security and NGOs delivering social work or FASD prevention services, should coordinate their aims, roles and policies and follow a holistic approach to address this complex and multi-dimensional social issue.

- Integrated prevention efforts should be undertaken on the different levels of the social environment by making use of all three levels of intervention in order to provide the necessary overlapping levels of reinforcement. Special attention should be given to the implementation of case management on the indicated level of prevention.

- Co-ordinating committees have to be established in every area by the Department of Health, in collaboration with the Department of Social Development, to ensure coordination of services and early identification of gaps in service delivery;

- Positive movements towards collaboration between non-government organisations and government departments have to be formalised into co-ordination agreements, with clear indications of responsibilities, referral systems and collaboration between the parties.

- A formal system of referrals has to be negotiated, agreed upon and implemented at regional level by the concerned government departments, such as the Departments of Health, Education, Social Services, Safety and Security, and non-government organisations and NGOs delivering social work or FASD prevention services.

In conclusion, it is recommended that a comprehensive programme for the prevention of FASD which includes a proper system of collaboration, co-ordination and referral that can be implemented nationally is developed. The goal of such a programme should not be to enhance FASD awareness only, but also to endorse a lifestyle that limits the possibility of exposing the fetus to alcohol. 


\section{REFERENCES}

ALBERTA PARTNERSHIP ON FETAL ALCOHOL SYNDROME. 1999. Guideline for the prevention of Fetal Alcohol Syndrome [Online]. Available: http://topalbertadoctors.org/PDF/complete\%set/FASDPrevention/FASD\%20Prevention/ FASD prevention guideline.pdf [Accessed: 01/05/2009].

ASTLEY, S.J. 2004. Fetal alcohol syndrome prevention in Washington State: evidence of success. Paediatric and Perinatal Epidemiology, 18(5):344-351.

CHAMBERS, C. 2006. Fetal alcohol syndrome. [Online] Available: http://www.emedicine.com/ped/topic 767.htm. [Accessed: 20/06/2008].

GREEFF, M. 2005. Information collection: Interviewing. In: DE VOS, A.S., STRYDOM, H., FOUCHÉ, C.B. \& DELPORT, C.S.L., (eds). Research at grass roots: for the social sciences and human service professions $\left(3^{\text {rd }}\right.$ ed.). Pretoria: Van Schaik, 286-313.

HANKIN, J.R. 2002. Fetal alcohol syndrome prevention research [Online] Available: http://pubs.niaaa.nih.gov/publications/arh26-1/58-65.htm [Accessed: 02/06/2010].

HOYME, H.E., MAY, P.A., KALBERG, W.O., KODITUWAKKU, P., GOSSAGE, J.P., TRUJILLO, P.A., BUCKLEY, D.G., MILLER, J.H., ARAGON, A.S., KHAOLE, N., VILJOEN, D., JONES, K.L. \& ROBINSON, L.K. 2005. A practical clinical approach to diagnosis of fetal alcohol spectrum disorder: Clarification of the 1996 Institute of Medicine criteria. Pediatrics, 115(1):39-47.

MARAIS, S. 2006. Drinking during pregnancy. [Online] Available: http://www.mrc. ac.za/mrcnews/dec2006/drinking.htm [Accessed: 06/06/2008].

MAY, P.A. \& HYMBAUGH, K.J. 1989. A macro-level fetal alcohol syndrome prevention program for Native Americans and Alaska Natives: Description and evaluation. Journal of Studies on Alcohol, 50(6):505-518.

MAY, P.A. 1995. A multiple-level, comprehensive approach to the prevention of fetal alcohol syndrome (FAS) and other alcohol-related birth defects (ARBD). The International Journal of the Addictions, 30(12):1549-1602.

MAY, P.A., GOSSAGE, J.P., MARAIS, A.S., ADNAMS, C.M., HOYME, H.E., JONES, K.L., ROBINSON, L.K., KHAOLE, N.C.O., SNELL, C., KALBERG, W.O., HENDRICKS, L., BROOKE, L., STELlAVATO, C. \& VILJOEN, D.L. 2007. The epidemiology of fetal alcohol syndrome and partial FAS in a South African community. Drug and Alcohol Dependence, 88: 259-271.

MAY, P.A., MILLER, J.H., GOODHART, K.A., MAESTAS, O.R., BUCKLEY, D., TRUJILLO, P.M. \& GOSSAGE, J.P. 2007. Enhanced case management to prevent fetal alcohol spectrum disorders in Northern Plains communities. Maternal and Child Health, 12:747-759.

MAY, P.A., GOSSAGE, J.P., MARAIS, A.S., HENDRICKS, L.S., SNELL, C.L., TABACHNICK, B.G., STELlAVATO, C., BUCKLEY, D.G., BROOKE, L.E. \& 
VILJOEN, D.L. 2008. Maternal risk factors for fetal alcohol syndrome and partial fetal alcohol syndrome in South Africa: a third study. Alcoholism: Clinical and Experimental Research, 32(5):738-753.

MAY, P.A. 2011. Feedback meeting to the community. Weltevrede Estate, Bonnievale. 29 September 2011.

McKINSTRY, J. 2004. Using the past to step forward: fetal alcohol syndrome in the Western Cape Province of South Africa [Online] Available: http://www. pubmedcentral.nih.gov/articlerender.fcgi?artid=1449323 [Accessed: 20/06/2008].

MILLER, D. 2005. Students with fetal alcohol syndrome: New developments and intervention suggestions [Online] Available: http://www.newhorizons.org/spneeds/ inclusion/collaboration/miller.htm [Accessed: 23/06/2008].

OTT, K.M., QUINN, L. \& THOMPSON, S.J. 2004. A social ecological analysis of fetal alcohol spectrum disorders prevention programming. Journal of Fetal Alcohol Syndrome, 2(e11):1-5.

PARRY, C.D.H. 2005. A review of policy-relevant strategies and interventions to address the burden of alcohol on individuals and society in South Africa. South African Psychiatry Review, 8:20-24.

PARRY, C.D.H. 2011. Feedback meeting to the community. Weltevrede Estate, Bonnievale. 29 September 2011

SOUTH AFRICA. 2006. Integrated Service Delivery Model towards improved social services. ?

STRATTON, K. 1996. Prevention of fetal alcohol syndrome. In: STRATTON, K., HOWE, C. \& BATTAGLIA, F. (eds) Fetal alcohol syndrome diagnosis, epidemiology, prevention and treatment. Washington DC: National Academy Press.

STRYDOM, H. 2005. Sampling and sampling methods. In: DE VOS, A.S., STRYDOM, H., FOUCHÉ, C.B. \& DELPORT, C.S.L. Research at grass roots: for the social sciences and human service professions $\left(3^{\text {rd }}\right.$ ed $)$. Pretoria: Van Schaik Publishers, 192204.

URBAN, M., CHERSICH, M.F., FOURIE, L.A., CHETTY, C., OLIVIER, L. \& VILJOEN, D. 2008. Fetal alcohol syndrome among grade 1 schoolchildren in the Northern Cape Province: Prevalence and risk factors. South African Medical Journal, 98(11):877-882.

VILJOEN, D., CROXFORD, J., GOSSAGE, J.P., KODITUWAKKU, P.W. \& MAY, P.A. 2001. Characteristics of mothers of children with fetal alcohol syndrome in the Western Cape province of South Africa. Journal of Studies on Alcohol, 63:6-17. 
386

VILJOEN, D.L., GOSSAGE, J.P., BROOKE, L., ADNAMS, C.M., JONES, K.L., ROBINSON, L.K., HOYME, H.E., SNELL, C., KHAOLE, N.C.O., KODITUWAKKU, P., ASANTE, K.O., FINDLEY, R., QUINTON, B., MARAIS, A.S., KALBERG, W.O. \& MAY, P.A. 2005. Fetal alcohol syndrome epidemiology in a South African community: A second study of a very high prevalence area. Journal of Studies on Alcohol, 66:593-604.

Ms Marlene de Vries, (Postgraduate student); Prof Sulina Green, Department of Social Work, University of Stellenbosch, Stellenbosch, South Africa. 